\title{
EDITORIAL
}

\section{A new generation of Environmental Conservation}

Few international journals can claim to have addressed environmental issues as thoroughly from a scientific stand-point, as comprehensively in geographic and disciplinary terms, or for as long a period of time, as has Environmental Conservation. This is thanks to an impressive list of contributors, many of them leaders in this vast field of disciplines and issues, but it is above all a tribute to Nicholas Polunin Sr. the founding Editor. He had devoted almost a quarter of a century of outstanding duty to this journal when he completed editing volume 11 at the age of 86. Environmental Conservation was begun by him when he recognized that a more broadly-based scientifically-oriented journal was required than was then currently available. Environmental Conservation was born in that first great period of environmental concern which seemed to reach a crescendo in the 1970s, before being swallowed up, or so it appeared, by the economic revolutions of the 1980s. The journal's stalwart Editor, however, worked on through those years, and Environmental Conservation has more than survived. The journal stands as an unique record of environmental concerns and studies as broad in scope as might be imagined for one quarterly publication.

There is little doubt that environmental concerns are again a major focus of political, and scientific, activity around the world. Oil spill effects and oil-rig disposals, impacts of nuclear testing, greenhouse-gas emissions, human population growth and its consequences, water and air pollution, means available for waste disposal, advances in recycling technology, chronic overfishing, destruction of forests, continuing land degradation and dwindling water resources, are a few environmental issues which have attracted very widespread attention in the last few months. How, in a different work from that of the 1970s, can Environmental Conservation again play a decisive role in recording such matters, helping disseminate scientific research on the underlying problems and fostering reasoned debate about the appropriate means of solving the most pressing problems of the day? For several months now I have been considering how best to address such demands.

I have made many specific decisions about the reincarnated journal as a result. Encironmental Conservation now has an outstanding publisher. I have appointed a small team of Associate Editors to help the journal do justice internationally to 'environmental science' through stronger links across the vast range of disciplines involved. These Associates will certainly help to enhance the flow of highquality information from their particular geographical (North America, South America, Europe, Africa and Australia) and disciplinary (including ecology, law, history and security) stand-points, which by design are very disparate. There are new names also among the Advisory Editors, the purpose in this case being to aug- ment the accumulated geographical and disciplinary expertise of the combined board.

The internal structure of the journal has changed. There is room for more interaction among contributors and readers in the new Comment section. Most of the journal's space will be taken up with substantive original papers, whether based on research, or on a review of nature. There are new procedures for better controlling the scientific quality of such papers. I intend to keep each issue of the journal as comprehensive as.I can manage for the time being in terms of subject matter. I view the Book Reviews and Meeting Reports sections as being vital also to the purpose of comprehensively recording environmental concerns and of disseminating the results of original studies, so I hope if anything to strengthen these sections. In this issue you will find nine Meeting Reports from around the world, and five Book Reviews. The format of contributions has changed; I believe it is now more in conformity with other similar publications. Prospective contributors should read the new Instructions before submitting any paper to me for consideration as there are many changes. In addition, the journal has a new cover to signal its rebirth. No doubt there are many other ways in which this journal might adapt to its role more fully, and consequently I ask you, the reader, in the coming months to let me have your suggestions as to what you think these adaptations might be.

The need for a journal which comprehensively addresses environmental issues is as great as ever. I particularly see Environmental Conservation as helping to bridge what I consider to be a serious gap between science and management in matters of 'the environment', and in this it must aspire to being eclectic. So it is that in this first issue of Volume 23 that there are contributions on tropical montane forest biodiversity, on coastal zone management, on protected area buffer zones, on greenhouse-gas emissions from tropical reservoirs, on international policies on the tropical timber trade, on losses of wetlands and seagrasses, on water quality of rivers, on medicinal plants and on the concept of environmental refugees. The geographical span is of the widest: from the global, through processes acting at the scale of whole countries (India, Germany) to specific areas, such as in part of the Himalayas and Peru, Hong Kong and Madagascar. Rosa, Schaeffer and dos Santos are the first contributors of a. Comment to this journal, addressing an earlier paper by Philip Fearnside; in the next issue Fearnside will be responding to this. I already have strong indications that this Comment section is going to be popular.

Welcome to a new generation of Environmental Conservation! Nicholas V. C. Polunin

Editor 